\title{
O DEFEITO DA LEI UNIVERSAL DO ENTENDIMENTO NA FENOMENOLOGIA DO ESPÍRITO DE HEGEL
}

\author{
Eduardo F. Chagas ${ }^{1}$
}

\section{Resumo:}

Hegel chama a atenção para o fato de que a lei é necessária, mas sua necessidade não é uma necessidade, mas uma palavra vazia, abstrata, visto que ela é meramente uma definição ou um conceito do entendi mento, uma identidade formal ou uma essência, na qual não está contida a existência; ou, com outras palavras, a lei como lei, necessária, não está posta no objeto mesmo. Essa lei universal, enquanto força simples ou diferença interna, é obra do entendimento, por isso seu aspecto necessário não é real, exprime apenas a própria necessidade do entendimento; a lei universal é aquela diferença interna, a diferença inerte, puramente subjetiva, que reside somente nas palavras do entendimento; uma diferença sem diferença, uma diferença que não exprime nenhuma diferença do objeto mesmo $\left(\$ 154^{\circ} \mathrm{PhG}\right)$. Se as diferenças nada são em si, pois elas têm o mesmo conteúdo, a mesma constituição, a saber, a diferença interior, a diferença única da lei, dada pelo entendimento, então a diferença como diferença de conteúdo, isto é, do objeto, está, na lei geral (na pura força), descartada. Assim sendo, a explicação (Erklärung) que descreve os diversos momentos ou ciclos constituídos da lei necessária, universal, recai não no objeto, mas só no entendimento, resultando daí um movimento analítico, puramente tautológico, formal do entendimento consigo mesmo. Nesse movimento tautológico, o entendimento deixa de lado o objeto e descobre somente a si mesmo; ele nada diz acerca do objeto mesmo, mas apenas persiste no seu próprio objeto, que é a unidade tranquila do objeto, o reino calmo das leis universais, elaboradas por ele mesmo $\left(\$ 155^{\circ}\right.$ da $\left.\mathrm{PhG}\right)$.

Palavras-chave: Consciência, Entendimento, Lei universal.

\begin{abstract}
:
Hegel points to the fact that the law is necessary, but its existence is not a necessity since it is an abstract word stripped of meaning, being merely a definition or a concept for understanding, that is, a formal identity or essence which holds the existence; or, in another words, the law in itself, which is necessary, it is not inserted in the same object. That universal law as simple force or internal difference is the output of the understanding, therefore its necessary aspect is not real, and it spells out the very need of understanding; the universal law is the afore-mentioned internal difference, purely mental, that lodges itself in the words; a difference of understanding only; a difference that spells out no difference from the object itself ( $\$ 154$ from $\mathrm{PhG})$. If differences are not anything by themselves, for they hold the same content and constitution, namely, interior difference and the sole law difference, as given by understanding, the

\footnotetext{
1 Doutor em Filosofia; professor da Graduação e da Pós-Graduação do Curso de Filosofia da Universidade Federal do Ceará (UFCE) e colaborador do Programa de Pós-Graduação da Faculdade de Educação (FACED) da UFC. Bolsista de Produtividade em Pesquisa do CNPq. E-mail: ef.chagas@uol.com.br.
} 
difference as difference of content, that is, from the object, is found in the general law (pure force) which was discarded. Being this the case, the explanation (Erklärung) that describes the several moments or cycles that constitute the necessary universal law is not directed towards the object, but just towards the understanding only from which issues an analytical purely tautological movement which is proper to understanding itself. Within that tautological movement, understanding leaves out the object and unveils itself only; it does not say anything about the object itself, but just holds to its own object which is the object's quiet unity, the peaceful kingdom of universal laws which are created by itself ( $§ 155$ from $\mathrm{PhG})$.

Keywords: Consciousness, Understanding, Universal law.

\section{Introdução}

No terceiro capítulo complicadíssimo, árduo ${ }^{2}$, da Fenomenologia do Espírito, intitulado "Força e Entendimento" - identificamos indiretamente posições da ciência e da filosofia dos séculos 17 e 18, particularmente as de Galileu, Locke, Newton, Leibniz, Kant e da filosofia romântica da natureza. Hegel apresenta também aqui a nova experiência realizada pela consciência. Neste momento dialético, a consciência suprassume a certeza sensível - o nível do ver, ouvir, tocar etc. - e reúne as contradições da percepção num universal incondicionado (unbedingte Universale) $\left(\S 132^{\circ}\right)^{3}$ que ela toma, de agora em diante, como seu objeto verdadeiro e essencial, objeto esse formado por uma "reflexão interna" sobre si mesmo (o retorno a si) a partir da relação para-comoutros. Segundo Hegel, a consciência não toma consciência disso, quer dizer, ela não reconhece, porém, ainda a si mesma nesse objeto refletido. Nós, filósofos, diz ele, sabemos, através de uma análise filosófica, e a experiência da consciência irá mostrar isto, a saber, que aquilo, de que chamamos o sentido próprio do objeto, reflete mesmo a estrutura da consciência, ou, com outras palavras, que esse objeto (o universal incondicionado) e a consciência são uma coisa só, uma reflexão só, mas a consciência, como dito, não sabe disso. Importa ver, pois, como ela examina, a seu modo, esse seu novo objeto: o objeto (a coisa, a realidade) não posto pelos sentidos, pela percepção, que o compreende meramente de forma externa e o tem, do ponto de vista químico,

\footnotetext{
2 "A dialética da força é", diz Gadamer, "um dos tópicos da obra de Hegel, que ele mesmo comentou mais profundamente, posto que são tópicos que não só aparecem na Fenomenologia, mas também, e com mais amplitude de análise, na Lógica ou na Enciclopédia." (GADAMER, 2000, p. 53).

${ }^{3}$ No decorrer do artigo será anunciado entre parênteses o número dos parágrafos da versão adotada da Fenomenologia do Espírito para fins de referência, no entanto, as citações da obra serão anunciadas no texto segundo o padrão da Revista Dialectus.
}

\begin{tabular}{|l|l|l|l|l|}
\hline Qedista Qialectus & Ano 2 & n. 3 & Julho-Dezembro 2013 & p. 1-17 \\
\hline
\end{tabular}


atomístico, decomposto em muitos objetos com suas propriedades, mas como força e jogo de forças, esclarecidos pelas leis, dadas pelo entendimento; quer dizer, o objeto como forças e jogo de forças, que exercem entre si uma ação recíproca, que estão por trás dos fenômenos, das propriedades da coisa, e como leis, que governam essas forças e fenômenos, leis essas elaboradas pelo entendimento.

O novo objeto, o universal, se apresenta de modo plenamente constituído (formulado, "modelado"), e a consciência se torna, agora, para si mesma consciência concebente (entendimento) (Verstand), quer dizer, se porta como consciência que concebe (entende) o objeto. Nesse universal, a consciência nega e abandona aquelas dualidades, aquelas contradições (essencial e inessencial, coisa e suas propriedades, uno e múltiplo, sujeito e objeto, ou saber e objeto) da consciência percebente $\left(\$ 134^{\circ}\right)$ e põe como a mesma essência a unidade do ser-para-si (o uno) e do ser-para-outro (o múltiplo), não só na forma em que concernem esses momentos, um em relação ao outro, mas também no próprio conteúdo. Consequentemente, qualquer objeto possível tem como essência esse conteúdo de ser-para-si e de se relacionar com-um-outro, ou seja, de ser um universal incondicionado (unbedingt).

Apesar do universal incondicionado ser o objeto da consciência concebente, emergem nele aqueles dois momentos que se apresentavam inicialmente à percepção $\left(\S 135^{\circ}\right)$ : o múltiplo, a multidão das propriedades sensíveis, das diferenças ou a multiplicidade das "matérias subsistentes" e a unidade (o uno em-si refletido) que excluia de si toda multiplicidade, que "aniquilava" a independência das "matérias subsistentes" (das propriedades do objeto), que são também para-si, livres e em oposição às outras. É evidente que esses momentos se apresentam doravante na incondicionalidade do universal não separados um do outro, mas pensados um com o outro, suprassumidos um ao outro, e o que se põe é apenas a passagem (o "transitar") de um para outro

O entendimento tem por objeto o passar constante do uno (da unidade) para o múltiplo (a diversidade) e do múltiplo para o uno. Esses dois momentos não estão separados, pois as "matérias independentes" (a multiplicidade), embora sejam cada uma para si, autônomas, estão numa unidade estreita que as subsistem, cada uma está onde a outra está, e a unidade é, com efeito, essa multiplicidade de matérias independentes e indiferentes $\left(\S 136^{\circ}\right)$. Quer dizer, a diversidade, posta como independente, passa imediatamente à unidade, e a unidade se desdobra nos independentes, e estes voltam à unidade, e assim sucessivamente. É precisamente esse veículo, esse processo, esse

\begin{tabular}{|l|l|l|l|l|}
\hline Qevista Qialectus & Ano 2 & n. 3 & Julho-Dezembro 2013 & p. 1-17 \\
\hline
\end{tabular}


movimento, constante de um para o outro, que aparece ao entendimento inicialmente como uma forma objetiva, que será, para ele, a força (die Kraft). Esta concentra, portanto, em si a matéria, isto é, as qualidades materiais desconexas da coisa, sendo, assim, um uno refletido em si, um meio universal, de múltiplas matérias existentes, de unidades individuais. Com isto, Hegel se aproxima aqui de diversos filósofos, entre outros, por exemplo, de Locke, que vê nas qualidades a força da substância; de Leibniz, que julga impossível a unidade na matéria isolada, passiva, tomando, pelo contrário, a força como a verdadeira natureza das coisas; de Kant, que entende os corpos materiais como equilíbrio de forças, a saber, de forças de atração e repulsão (Cf. SIEP, 2000, p. 92).

No já mencionado capítulo "Força e Entendimento" da Fenomenologia, Hegel apresenta, inicialmente, o conceito e a realidade da força. $\mathrm{O}$ entendimento distingue, na concepção de Hegel, dois momentos da força: a força em si (die Kraft an sich), a força "reprimida", "recalcada" ou concentrada em si mesma (a potência), que é a força propriamente dita, e a exteriorização da força (die Äusserung der Kraft), a força como exteriorização (o ato) das propriedades, como manifestação ou expansão de si mesma no meio das diferenças, das matérias independentes e distintas. Só é força propriamente dita, se ela contém esses dois momentos, isto é, se ela manifesta ou põe para fora de si, o que ela tem dentro de si, mas, na exteriorização, ela se conserva como força, se mantém em si mesma, já que ela é apenas exteriorização do que é em si e não há nada atrás dela. Esses dois momentos diferentes - a força recalca em si e força enquanto exteriorização - é apenas uma distinção do entendimento, do pensamento, ou conceito dele, e não a realidade da força mesma. Na verdade, a força não é exclusivamente um de seus momentos opostos, os quais são inseparáveis, mas a passagem de um momento ao outro, pois tanto um quanto o outro são ela própria. No objeto (o universal incondicionado), a força é igualmente para si mesma o que é para-um-outro; ela tem a diferença nela mesma, pois ela não é outra coisa que um ser-para-outro.

$\mathrm{Na}$ força há, como dito, um processo de dois momentos, “que, sem cessar, se fazem independentes, para de novo se suprassumirem" (HEGEL, 1999, p. 98). Este movimento se assemelha aquele que ocorria na consciência percebente, na qual o percebente (o sujeito) e o percebido (o objeto) apareciam como separados, distintos (cada qual "refletido sobre si" ou "para-si"), embora eles fossem ao mesmo tempo um só e indistintos, formando entre eles uma unidade no ato do conhecimento. Agora, no entendimento, tal movimento encontra-se presente nos dois momentos da força, os quais são dois extremos para si existentes, mas que formam também uma unidade (o termo

\begin{tabular}{|l|l|l|l|l|}
\hline Qevista Qialectus & Ano 2 & n. 3 & Julho-Dezembro 2013 & p. 1-17 \\
\hline
\end{tabular}


médio entre eles) e só existem por meio dela. Assim, esse movimento, que na percepção se apresentava como autodestruição de conceitos contraditórios, é aqui, no entendimento, o movimento da força, cujo resultado se produzirá o universal incondicionado como algo não-objetivo ou, melhor dizendo, como o interior das coisas.

\section{O interior ou o fundo das coisas}

Hegel concebe a força como o interior (das Innere) do objeto, como o interior que movimenta o próprio jogo de forças presente no objeto. Hegel mostra que a consciência concebente (o entendimento) apreende, em princípio, o seu objeto, a força, a partir de dois universais: o primeiro universal, o universal imediato, donde o entendimento parte, é a força como "substância", a força realçada em si, concentrada em si mesma e subsistente, que, para ele, é um objeto real; então, o segundo universal é um universal mediatizado pela negação do universal imediato, ou seja, o negativo da força sensível objetiva, que é a força em sua verdadeira essência, tal como ela é em si e para si. Esse segundo universal, que só é objeto para o entendimento, é o interior ${ }^{4}$ das coisas como interior, idêntico ao conceito como conceito $\left(\S 142^{\circ}\right)$.

O entendimento não tem, entretanto, uma relação imediata com esse interior, com essa essência verdadeira das coisas; só o tem através de um meio-termo, de uma mediação, que é o jogo de forças $\left(\$ 143^{\circ}\right)$. Este meio-termo (o jogo de forças), que aproxima o entendimento ao interior das coisas, é o "ser das forças", que, ao se manifestar, desaparece. O meio-termo é, para o entendimento, um evanescente e, por isso, se chama fenômeno (Erscheinung); ele é um ser que imediatamente é em si mesmo um não-ser, uma aparência de ser, sem consistência e estabilidade em si mesmo. O todo, a totalidade, dessa experiência é o universal que constitui o interior ou, como diz Hegel, o jogo de forças (das Spiel der Kräfte) refletido sobre si mesmo, posto agora positivamente como um objeto em-si existente.

O ser da certeza sensível e o da percepção têm, agora, somente uma significação negativa (nula), pois são, aqui, apenas fenômeno (manifestação fenomênica), que aponta, no entanto, para um interior objetivado. O entendimento (a consciência

\footnotetext{
${ }^{4}$ Gadamer (2000, p. 56) também destaca a singularidade do entendimento frente as etapas anteriores da consciência, como a certeza sensível e a percepção: "Uma coisa é clara a esse respeito: olhar o interior é coisa do entendimento, e não já da percepção sensível. [...] O objeto do 'pensar puro' se caracteriza obviamente pelo fato de não estar dado de modo sensível."
}

\begin{tabular}{|l|l|l|l|l|}
\hline Qenista Dialectus & Ano 2 & n. 3 & Julho-Dezembro 2013 & p. 1-17 \\
\hline
\end{tabular}


concebente) faz desse interior, enquanto reflexão interna das coisas, o verdadeiro e distingue dessa reflexão interna a sua própria reflexão, sua reflexão em si mesma.

Isto se dá porque o entendimento concebe ainda o interior com algo externo e oposto a ele, como consequência ou desdobramento de um fenômeno puramente objetivo evanescente, não estando, pois, ainda consciente de sua presença nele (no interior), ou seja, que ele (o interior) é já um conceito seu (do entendimento); ele lida com esse interior enquanto conceito, mas ainda não se deu conta disso. Ou melhor: "O interior, portanto, é para ela o conceito; mas a consciência ainda não conhece a natureza do conceito" (HEGEL, 1999, p. 103). Esse interior é para o entendimento o verdadeiro, o absoluto-universal, visto que ele está livre da oposição entre a universalidade e a singularidade, entre o uno e o múltiplo; ele é, como dito, o objeto do entendimento, objeto em que se manifesta pela primeira vez, ainda que de modo imperfeito, a razão $\left(\S 144^{\circ}\right)$. Tal interior irá se patentear aqui, no entanto, como um além permanente sobre o aquém evanescente, ou seja, como um mundo supra-sensível (verdadeiro), pairado acima e para além do mundo fenomênico, sensível (aparente). Esta concepção do entendimento de um universal dado por ele, e não de um universal do sensível em sua alteridade, do elemento comum às aparências do sensível, de um interior verdadeiro, absolutamente verdadeiro, de um mundo supra-sensível como o mundo verdadeiro, a parte e por cima do mundo sensível, percebido ou aparente, se assemelha, de certa forma, com as concepções platônica, cristã, galileana e newtoneana, que se caracterizam por tomar o universal como o que permanece no que desaparece, ou como o mais além que permanece sobre o aquém que desvanece. Daqui em diante, veremos um silogismo que tem por extremos o interior, ou fundo das coisas, e o entendimento, e, por intermédio, o mundo fenomênico $\left(\$ 145^{\circ}\right)$, pois o movimento desse silogismo irá demonstrar as experiências, quer dizer, as ulteriores determinações daquilo que o entendimento faz através desse meio-termo, em busca do fundo das coisas, do interior da realidade. É também partir daqui que surge um terceiro momento que diz respeito, sobretudo, à relação entre o mundo supra-sensível (übersinnliche Welt) e o mundo sensível (sinnliche Welt).

Para a consciência concebente (o entendimento), o interior da coisa é um puro além (um além dela), porque ela ainda não se reconhece nele; ele é para ela apenas o negativo do fenômeno, o vazio (o nada) que o nega, mas representado por ela positivamente como um universal simples $\left(\S 146^{\circ}\right)$. Esta maneira de se pensar assemelha-se com a posição filosófica de alguns pensadores (como, por exemplo, Kant),

\begin{tabular}{|l|l|l|l|l|}
\hline Qevista Dialectus & Ano 2 & n. 3 & Julho-Dezembro 2013 & p. 1-17 \\
\hline
\end{tabular}


para os quais o interior (a essência) das coisas pode ser decerto pensado, mas não conhecido; o interior é, pois, incognoscível. Sem dúvida que desse interior, tal como ele é aqui abordado, não pode haver nenhum conhecimento. Isto se dá, na concepção de Hegel, não porque a razão, como pensa Kant, seja míope ou limitada, mas justamente porque esse interior é posto como o "além" da consciência ou concebido como o vazio (um vácuo), separado e oposto ao mundo percebido, e no "além" ou no vazio nada se pode conhecer.

Querer conhecer o interior dessa maneira é, segundo as palavras de Hegel, a mesma coisa que colocar um cego diante das riquezas do mundo supra-sensível e pedirlhe para ver o conteúdo dela, ou então pôr um vidente no meio das puras trevas ou da pura luz, pois tanto lá como aqui ele nada veria; quer dizer, tanto o cego quanto o vidente não enxergariam a abundância de coisas que estariam diante deles. Se o interior, assim pensado, é incognoscível e, portanto, inacessível, a consciência concebente acredita que o melhor a fazer seria abandoná-lo de vez, contentando-se apenas com o fenômeno. Mas com esta alternativa, ela se depara com um problema: atém-se ao fenômeno e o toma por verdadeiro, embora saiba não ser ele o verdadeiro, ou, para preencher o vazio, o esvaziamento das coisas objetivas, que veio a ser com o abandono de seu interior, ela o preenche com seus próprios devaneios, sonhos e fantasias, no intuito de disfarçar a ausência desse interior.

É necessário atentar que o interior (ou o “além” supra-sensível) não é, para Hegel, o vazio, pois ele provém do fenômeno, da aparência. E, embora o fenômeno não seja a verdade, ele (o fenômeno) é a mediação do interior, pois, por meio dele (do fenômeno), o interior se põe, se manifesta; o interior se manifesta no fenômeno, e o fenômeno é a manifestação do interior; assim, o fenômeno não é o fenômeno de algo oposto, diferente, do interior, mas sim a própria essência, o conteúdo, a condição e a implementação dele (do interior, do supra-sensível). Este é, pois, o fenômeno posto tal como ele é em sua verdade, isto é, não uma mera exteriorização de uma força, que se anula, que se paralisa, mas fenômeno que é a totalidade da realidade, o fenômeno da essência, pois a essência do fenômeno é ser fenômeno, ou seja, ser algo evanescente, passageiro, algo que se suprassume, que deixa de ser o que é, mas sendo; portanto, o interior (o supra-sensível) é o fenômeno (o sensível, o percebido) como fenômeno posto, tomado na sua plenitude. Isto não quer dizer que o interior (o supra-sensível) seja o mundo sensível imediato ou o mundo tal como é para a certeza sensível (para a sensibilidade) e para a percepção, porque o fenômeno não é imediatamente o mundo do

\begin{tabular}{|l|l|l|l|l|}
\hline Qepista Dialectus & Ano 2 & n. 3 & Julho-Dezembro 2013 & p. 1-17 \\
\hline
\end{tabular}


saber sensível e do perceber com um aí existente, mas tal mundo como suprassumido ou posto em sua plenitude, em sua totalidade, como interior. Portanto, quando se diz que o interior (o supra-sensível) não é o fenômeno, não se entende aqui por fenômeno o fenômeno no seu sentido estrito (verdadeiro), mas como sinônimo de mundo sensível na sua própria efetividade real.

Evidenciamos que o interior das coisas era inicialmente, para o entendimento, um universal incondicionado, um “em-si universal ainda não-condicionado", e o jogo de forças tinha não só uma significação negativa (de não-ser em si), mas também positiva, qual seja: ser o mediador entre o entendimento e o interior. Através dessa mediação positiva, quer dizer, por meio do movimento das forças, o interior irá, agora, neste ponto, se implementar, ganhar um conteúdo para o entendimento $\left(\S 148^{\circ}\right)$. Hegel nos mostra como isto ocorre: no jogo de forças, diz ele, aparece, como primeiro momento, um único conteúdo, constituído pela diferença entre as forças: A diferença de forma força solicitada e força solicitante - e a de conteúdo - força recalcada em si como una (o passivo) e força desdobrada como múltipla (o ativo). Aqui ocorre apenas a troca imediata de determinações ou a permuta absoluta entre as forças: A solicitada se converte em solicitante, e a solicitante em solicitada. Como essas duas diferenças são, porém, a mesma coisa, quer dizer, a diferença de forma é o mesmo que a diferença de conteúdo, desaparece, então, toda a diferença entre as forças particulares, as duas diferenças se tornam uma só. Assim, não há nem força recalcada, nem solicitante, mas uma única diferença, a diferença enquanto tal, à qual as forças opostas estão reduzidas. Esta diferença constante, idêntica, como um universal, como um simples, que permanece tranquilamente no que desaparece, isto é, no jogo de forças, que subsiste na instabilidade fenomênica, na incessante troca de seus momentos, é o verdadeiro e constitui, precisamente, a lei do fenômeno, da natureza ou da força da coisa. A lei não é a mudança, mas essa diferença simples que repousa no interior como uma imagem constante do fenômeno cambiante, sempre instável. O interior (o mundo supra-sensível) é, precisamente, o mundo das leis (die Welt der Gesetze) como imagem calma, tranquila, do mundo sensível; ele é, portanto, o reino calmo das leis (Reich der Gesetze), como algo não só para "além” do mundo fenomênico-imediato, do mundo percebido como mudança constante, mas também presente nele (no mundo fenomênico) ( $\left.\$ 149^{\circ}\right)$.

O fenômeno (a coisa na sua dimensão aparente e mutável) tem o seu conteúdo naquela diferença simples, universal, que se expressa na lei. Esta (o reino das leis ou o mundo supra-sensível) é para o entendimento o interior ou a verdade (die Wahrheit), a

\begin{tabular}{|l|l|l|l|l|}
\hline Qevista Dialectus & Ano 2 & n. 3 & Julho-Dezembro 2013 & p. 1-17 \\
\hline
\end{tabular}


realidade (die Wirklichkeit), do fenômeno, do mundo sensível. Mas é necessário atentar aqui para o fato de que a lei (universal) é só uma parte dessa verdade, já que ela não preenche completamente as diferentes leis do fenômeno. A lei (universal) está, como acima fora dito, presente no fenômeno, mas ela não exprime a sua totalidade, não é toda a sua presença, porque ela tem uma realidade efetiva diferente da dele, contraposta a ele. "Portanto, resta ao fenômeno para si um lado que não está no interior" (HEGEL, 1999, p. 106) - na diferença -, e isto se dá precisamente porque o fenômeno ainda não atingiu, em verdade, essa diferença, ainda não está posto completamente como fenômeno, como um ser-para-si suprassumido $\left(\$ 150^{\circ}\right)$. Esta debilidade, este defeito da lei, próprio do entendimento, recai também sobre ela própria, que tem em si a determinidade, a diferença mesma, mas, na lei geral (dada pelo entendimento), ela só a tem de modo indeterminada, indiferente para com os seus termos; ou, de outro modo, a lei se apresenta como lei determinada, como uma pluralidade empírica de leis particulares, e não com lei em geral, universal. Só que essa multiplicidade de leis contradiz o princípio do entendimento, para o qual o verdadeiro é uma auto-inversão, um suprassumir do diferente, isto é, a identidade das diferenças, a unidade em si universal. Para resolver este problema, o entendimento faz coincidir as leis múltiplas numa só lei universal, ou seja, conduz distintas leis à unidade de uma única lei, como a verdade do objeto, como lei que deve dominar a realidade, explicar completamente todos os fenômenos. Nessa discussão acerca da lei única, uniforme, homogênea, dada pelo entendimento, Hegel utiliza, de certa forma, os exemplos das ciências da natureza de sua época, como a doutrina da eletricidade, a química e a mecânica modernas, os fenômenos do magnetismo, as teorias da medicina, dentre outras. Cita, por exemplo, aqui a lei da gravidade como lei universal dos corpos, isto é, a lei da atração universal, que regula (reúne em si) tanto a lei da queda dos corpos sobre a terra quanto a do movimento das esferas celestes. A lei única, universal, se torna, no entanto, superficial, vazia, pois, em vez de exprimir o conteúdo qualitativo das leis particulares ou de unificar as suas determinações diversas, acaba negando-as, não abarcando a totalidade das aparências, dos fenômenos. Assim sendo, a lei da atração universal é, por exemplo, apenas uma fórmula abstrata, o conceito da lei mesma, que se põe como existente, objetivado. Tal lei anuncia apenas que "tudo tem uma diferença constante com o outro" ou que toda realidade é regida por uma legalidade. Embora o entendimento pense "ter aí descoberto uma lei universal, que exprime a universal efetividade como tal", mas que, na verdade, tenha encontrado apenas “o conceito da lei mesma” (HEGEL, 1999, p. 107),

\begin{tabular}{|l|l|l|l|l|}
\hline Qevista Qialectus & Ano 2 & n. 3 & Julho-Dezembro 2013 & p. 1-17 \\
\hline
\end{tabular}


isto não deixa de ter mérito, já que se confronta com a representação vulgar, carente de pensamento, que acredita ser a realidade não regida por leis, mas dada de forma contingente, aleatória, e suas determinações puramente sensíveis e imediatas.

A lei geral (das allgemeine Gesetz), universal (o conceito puro de lei), como a lei da atração universal, opõe-se às leis determinadas, visto que a primeira (a lei geral) é considerada pelo entendimento como a essência, o verdadeiro interior das coisas, e a segunda (a pluralidade das leis empíricas), pertencente apenas a momentos evanescentes, à esfera do fenômeno ou da aparência sensível e imediata da coisa. Na verdade, a lei geral não só ultrapassa as leis determinadas, como ainda se volta contra si mesma, contrastando o seu próprio conceito $\left(\$ 151^{\circ}\right)$. Isto se dá porque a lei geral, tratada aqui pelo entendimento, ao acolher em si mesma, no seu interior, as leis determinadas, as nega, e, ao negá-las, nega a si mesma, já que ela, abstraídas dessas determinidades, dessas diferenças, torna-se uma unidade vazia. $\mathrm{Na}$ verdade, o conceito de lei, compreendido no seu verdadeiro sentido, tal como Hegel defende, deve captar as diferenças, que são momentos separados e independentes, e lhes dar uma unidade simples, que é a necessidade interior da própria lei.

Na concepção de Hegel, a lei se apresenta, portanto, de duas maneiras: a) uma, como expressão de leis particulares que são momentos diferentes e independentes; b) outra, como forma simples, refletida sobre si mesma, que é o aspecto necessário da lei e que se pode, novamente, chamar de força, não aquela força recalcada, posta pelo jogo de forças inerente ao objeto, mas a força em geral ou o conceito de força enquanto abstração do entendimento, que exprime a necessidade do vínculo entre os termos, que inclui em si o que atrai e o que é atraído $\left(\$ 152^{\circ}\right)$. Consideremos uma lei particular, por exemplo: a) a lei geral da eletricidade (voltagem) é a força (elétrica), a força simples das leis particulares, das cargas elétricas positivas e negativas; b) a lei geral da queda dos corpos, da gravidade, é a força, o simples de diferentes grandezas, dos diversos momentos do movimento, do tempo (da velocidade) decorrido, num espaço (numa distância) percorrido. Nessas leis gerais pode-se evidenciar que há diferenças concretas, leis particulares ou termos independentes entre si (carga positiva diferente da negativa, espaço diferente de tempo etc.), termos esses que têm essências neles mesmos, conteúdos distintos, onde um não contém necessariamente o outro, de modo que o vínculo, a relação, entre eles não é necessário, mas artificial (conceitual, analítico) $\left(\$ 153^{\circ}\right)$. A lei como lei, como força simples, elaborada pelo entendimento, é, pois, indiferente de ser positiva ou negativa, de ser espaço ou tempo; ela é única e necessária:

\begin{tabular}{|l|l|l|l|l|}
\hline Qevista Dialectus & Ano 2 & n. 3 & Julho-Dezembro 2013 & p. 1-17 \\
\hline
\end{tabular}


a lei tem "de ser dessa maneira", ou então "tem a propriedade de se exteriorizar assim"; ela "deve desdobrar-se assim, justamente porque deve" (HEGEL, 1999, p. 108). Hegel chama a atenção para o fato de que a lei dada pelo entendimento é necessária, mas sua necessidade não é aqui uma necessidade, mas uma palavra vazia, abstrata, visto que ela é meramente uma definição ou um conceito dele (do entendimento), uma identidade formal ou uma essência, na qual não está contida a existência; ou, com outras palavras, a lei como lei, necessária, não está posta na realidade, na coisa mesma. Essa lei geral, enquanto força simples ou diferença interna, é obra do entendimento, por isso seu aspecto necessário não é real, exprime apenas a própria necessidade do entendimento; a lei universal é aquela diferença interna, a diferença inerte, puramente subjetiva, que reside somente na linguagem, nas palavras do entendimento; uma diferença sem diferença, uma diferença que não exprime nenhuma diferença da coisa mesma $\left(\S 154^{\circ}\right)$.

Se as diferenças nada são em si, pois elas têm o mesmo conteúdo, a mesma constituição, a saber, a diferença interior, a diferença única da lei, dada pelo entendimento, então a diferença como diferença de conteúdo, isto é, da realidade, da coisa, está, na lei geral (na pura força), descartada. Assim sendo, a explicação (Erklärung) que descreve os diversos momentos ou ciclos constituídos da lei necessária, universal, recai não na realidade, na coisa (no objeto), mas só no entendimento, resultando daí um movimento analítico, puramente tautológico, formal, do entendimento consigo mesmo. Nesse movimento tautológico, o entendimento tem a lei ausente do princípio negativo da realidade, distinta do movimento da realidade, que, na verdade, a determina; ou seja, ele deixa de lado, e este é o seu grande defeito, a realidade mesma, o alternar-se enquanto tal, a coisa, e descobre somente a si mesmo; ele nada diz acerca da coisa mesma, mas apenas persiste no seu próprio objeto, que é a unidade tranquila da coisa, o reino calmo das leis universais, elaboradas por ele mesmo $\left(§ 155^{\circ}\right)$. Esse movimento tautológico do entendimento é, com palavras de Hegel, "um explicar que não somente nada explica, como também é tão claro que, ao fazer intenção de dizer algo diferente do que já foi dito, antes nada diz, mas apenas repete o mesmo" (HEGEL, 1999, p. 110). ${ }^{5}$ Hegel defende magistralmente que nesse formalismo, nesse movimento tautológico do entendimento, já contém, de forma invertida (como mundo

\footnotetext{
${ }^{5}$ Para exemplificar essa tautologia do explicar do entendimento, Gadamer se utiliza das leis fonéticas. Diz ele: "a este respeito se fala das leis de mutação fonética, que 'explicam' a mudança dos sons dentro da linguagem. Porém, as leis não são, naturalmente, nada distinto do que explicam. Não almejam, em absoluto, nenhuma outra pretensão. Toda regra gramatical tem o mesmo caráter tautológico. Com ela não se explica nada em absoluto, mas apenas se expressa meramente como uma lei que governa a linguagem, o que, em verdade, é a vida da linguagem." (GADAMER, 2000, p. 61).
}

\begin{tabular}{|l|l|l|l|l|}
\hline Qevista 2 ialectus & Ano 2 & n. 3 & Julho-Dezembro 2013 & p. 1-17 \\
\hline
\end{tabular}


invertido), em seu próprio objeto, na legalidade una e unitária, na lei geral, no mundo calmo, tranqüilo, das leis, o princípio da alteração, do alterar-se, do movimento por si dentro de si mesmo, da mudança absoluta mesma, que lhe fazia falta. Como? Que mudança é essa, se a lei universal é o reino calmo, sem "mudança", ou a diferença única sem diferença de conteúdo? Se analisarmos melhor o processo de explicação do entendimento, veremos que ele (o entendimento) é o contrário de si mesmo, uma vez que ele, ao buscar a necessidade da lei, estabelece uma diferença (a diferença do interior, a diferença única, universal, que é a lei), que, na verdade, não é diferença nenhuma, porque é privada de conteúdo, das determinações das leis particulares, e com isto acaba de novo suprassumindo-a como diferença. A mudança anunciada aqui é, precisamente, a mudança da diferença deixando de ser diferença, ou seja, o fluxo e o refluxo da diferença que, ao ser posta como diferença, é imediatamente abolida. Tal mudança já se apresentava antes no jogo de forças: neste, havia, com já vimos, a diferença entre as forças solicitada (recalcada sobre si) e solicitante (exteriorizada). Estas diferenças, em verdade, não eram diferenças nenhuma, e, por isso, se suprassumiam reciprocamente. Essa mudança e permuta da diferença, que ocorria só no fenômeno, no jogo de forças inerente ao objeto, penetra também no reino das leis, no mundo supra-sensível, no interior, que é objeto do entendimento; agora, não é mais no objeto, mas no entendimento que se experimenta o vir-a-ser, a alteração, a mudança, o movimento, que põe e imediatamente suprime a diferença.

A mudança (der Wechsel), que agora ocorre não no sensível (no sentido meramente sensível, material), na coisa mesma, mas no supra-sensível, no interior da coisa, é pura (reflexão dentro de si, refletido em si), já que o conteúdo de seus momentos é idêntico. Essa mudança, tal como o interior das coisas, é puro conceito, um conceito do conceito do entendimento, e vem a ser para o entendimento a lei do interior das coisas (a lei da lei) ou a lei da lei do próprio fenômeno, que se exprime assim: as diferenças não são diferenças nenhumas e, assim sendo, se suprassumem, ou o homônimo (o unívoco, o que tem o mesmo nome) se repele (tem nome diferente) e o heterônimo (o que tem nome diferente) se atrai (tem o mesmo nome) $\left(\S 156^{\circ}\right)$. Essa nova lei, "sem dúvida, é também [...] um ser interior igual-a-si mesmo; mas antes uma igualdade-consigo-mesma da desigualdade - uma constância da inconstância" (HEGEL, 1999, p. 111). A nova ou a segunda lei (do entendimento) -, ao afirmar que o igual (o idêntico) a si se repele (se torna desigual, diferente), e aquilo que é repelido se une (o desigual se torna igual ou o dessemelhante do semelhante), ou seja, ao afirmar a

\begin{tabular}{|l|l|l|l|l|}
\hline Qepista Dialectus & Ano 2 & n. 3 & Julho-Dezembro 2013 & p. 1-17 \\
\hline
\end{tabular}


igualdade na desigualdade, e a desigualdade na igualdade (a unidade da identidade e da diversidade) -, se opõe à primeira lei (também do entendimento, o interior, a lei tranquila do fenômeno), para qual a diferença permanecia sempre igual a si mesma.

A primeira lei do mundo fenomênico (o reino tranquilo das leis, o primeiro mundo supra-sensível do sensível) transmudou-se, pois, em seu contrário: inicialmente, tanto a lei quanto as suas diferenças permaneciam tranquilas, iguais, constantes; agora, na segunda lei (no segundo mundo supra-sensível), tanto a lei quanto as suas diferenças são transversões de si, o contrário delas mesmas, pois o igual se repele e o desigual se põe como igual. Só com esta determinação é que a diferença, de fato, é interior, lei (mundo supra-sensível) ou diferença mesma, efetivada, que é, precisamente, o igual enquanto desigual e o desigual como igual a si mesmo $\left(\$ 157^{\circ}\right)$. Para expressar a troca, essa mudança, sobretudo essa inversão de forças polares nas leis, como no magnetismo, na eletricidade, nos processos dos nervos e músculos, Hegel se utiliza do princípio da alteração, do termo inversão (Umkehrung, Verkehrung, Umschlag), "mundo invertido" (verkehrte Welt), o mundo invertido em si, o contrário a si, o volvido contra si, o contrário e o semelhante de si mesmo. ${ }^{6}$ Neste sentido, esse segundo mundo suprasensível é um mundo invertido, como "um espelho que troca os lados" e, na verdade, é uma inversão do mundo sensível (eine Umkehrung der Erscheinungswelt), o inverso da lei do mundo fenomênico, do primeiro mundo supra-sensível: enquanto o primeiro era apenas a elevação imediata do mundo percebido ao universal (do sensível ao inteligível, tal como a ascensão platônica do mundo da caverna ao mundo noético da idéia permanente), privado ainda de mudanças e alterações, o segundo mundo adquire o princípio da mudança, mas agora como um mundo invertido. Conforme a lei deste mundo invertido, o homônimo (o igual) da lei do mundo fenomênico se converte através do princípio da mudança no heterônimo (no desigual), e o desigual vem a ser o igual a si mesmo; o que, por exemplo, na lei do fenômeno, era doce, negro, no mundo invertido é amargo, branco $\left(\$ 158^{\circ}\right)$. Hegel vê a lei desse mundo invertido não só nas leis da natureza, mas também no mundo moral. Também aqui se invertem as ordens e as ações do mundo em seu contrário. Por exemplo, no castigo de um crime, pode ser expressa assim: o que naquele mundo fenomênico era indigno, desprezível e desonroso (mera vingança), neste, honra. Pois, "uma ação que no fenômeno é crime” pode "ser no

\footnotetext{
${ }^{6}$ Para Gadamer (2000, p. 49): "O mundo invertido constitui a mais árdua secção dentro do contexto geral da história da experiência da consciência que Hegel desenhou." Ele caracteriza "esta doutrina do mundo invertido, que está contida no capítulo sobre 'Força e Entendimento', como central no edifício inteiro da Fenomenologia do Espírito".
}

\begin{tabular}{|l|l|l|l|l|}
\hline Qepista Dialectus & Ano 2 & n. 3 & Julho-Dezembro 2013 & p. 1-17 \\
\hline
\end{tabular}


interior uma boa ação propriamente dita (um ato mau, ter uma boa intenção), o castigo ser castigo só no fenômeno; mas, em si ou num outro mundo, ser benefício para o transgressor" (HEGEL, 1999, p. 112-113, §159²). Quer dizer: o que, no fenômeno parece ser castigo, que desonra e destrói o homem, pode, no mundo invertido, transmudar-se em perdão, que o salva e lhe restitui a honra.

$\mathrm{Na}$ visão de Hegel seria supérfluo considerar, no entanto, esses dois mundos como dois mundos separados ou opostos: um, sendo o fenômeno (o mundo sensível, aparente), exterior, o mundo como é para um outro; e o outro, o mundo invertido (o mundo supra-sensível, verdadeiro), o interior, o mundo como é em-si. Se assim fosse, o que parece, no mundo sensível, doce ao paladar, seria em-si, no mundo invertido, amargo; ou o que é pólo norte no ímã do fenômeno, seria no seu em-si supra-sensível (no seu interior) pólo sul; ou, no sentido espiritual, uma ação que no fenômeno é crime, seria, no interior, uma boa ação. Esta superficialidade desdobra o mundo em dois: um deles, o mundo sensível, perceptível, que pode ser tocado (apontado), visto, "ouvido" ou "saboreado"; o outro, o inverso deste mundo, o mundo representado pelo entendimento, acessível apenas pela imaginação. Na verdade, os dois mundos são um só, quer dizer, momentos de um mesmo mundo, pois a inversão (o mundo invertido) não se efetiva de fora, exteriormente (em um outro mundo), mas está presente neste mundo mesmo, como o mundo verdadeiro, que se encontra escondido por trás do fenômeno. Por exemplo: o pólo positivo de uma pilha, que é o interior, o em-si, a essência do pólo negativo, é o mesmo que o pólo negativo presente na exterioridade da mesma pilha. Do mesmo modo, o crime tem sua inversão no castigo efetivo (na pena), que se lhe opõe, reconciliando o indivíduo transgressor, por meio da lei, com a sociedade; mas o próprio castigo tem, como Dostoiésvski mostra, no seu celebre romance Crime e Castigo, uma inversão nele mesmo, porque, através da lei efetivada, o castigo se suprassume a si mesmo, quer dizer, na lei aplicada se extingue o movimento da individualidade contra a lei, e o da lei contra a individualidade, e assim a coação pode ser libertação.

\section{O infinito como unidade dialética dos dois mundos}

Suprimida "a representação sensível da consolidação das diferenças num distinto elemento do subsistir" (HEGEL, 1999, p. 113), quer dizer, superada a oposição superficial, absoluta, que divide o mundo em dois mundos distintos (o fenomênico, aparente, e o essencial, oculto), tem-se agora a contradição em si mesma $\left(\$ 160^{\circ}\right)$, pois o

\begin{tabular}{|l|l|l|l|l|}
\hline Qevista Qialectus & Ano 2 & n. 3 & Julho-Dezembro 2013 & p. 1-17 \\
\hline
\end{tabular}


mundo supra-sensível, que é o mundo invertido, é para si o invertido, o invertido de si mesmo, isto é, é ele mesmo e o seu oposto numa unidade. Hegel designa, precisamente, esse princípio da inversão de algo em seu contrário, que constitui a estrutura da realidade, como infinitude (Unendlichkeit), pois só no infinito uma realidade é o contrário de si mesma, ou seja, já tem incluída o outro imediatamente em si mesma; só o que é em si contrário de si mesmo pode realizar apenas em si o tornar de um outro. Graça ao infinito, a lei se cumpre em si mesma como necessidade e todos os momentos do fenômeno são acolhidos no interior. O simples, o necessário da lei, é, portanto, o infinito, e isto quer dizer que: a) por meio do infinito, a lei é a força simples, fracionada em si mesma, ou a diferença mesma, na qual, como já vimos, o homônimo (o igual) como homônimo se repele para fora de si mesmo e o heterônimo (o desigual) enquanto heterônimo se identifica; b) através do infinito, a lei também unifica as frações em que se divide o movimento, pois nele as partes espaço e tempo, ou distância e velocidade, positivo e negativo, são momentos de uma unidade, são independentes e estão, ao mesmo tempo, unidos, e c) pelo infinito, a lei possibilita que as frações, os termos opostos (espaço e tempo, positivo e negativo), estejam numa relação recíproca, pondose e suprassumindo-se num todo, uma vez que os dois termos, ao serem o oposto de si ou terem o seu outro em si mesmos, constituem apenas uma unidade $\left(\S 161^{\circ}\right)$.

A esse infinito simples Hegel chama de "o sangue universal" ou "a essência" da vida, "a alma do mundo", que não é perturbado nem interrompido por nenhuma diferença, já que ele é todas as diferenças e a suprassunção de todas, por isso ele "pulsa em si sem mover-se, treme em si sem inquietar-se" (HEGEL, 1999, p. 115). O infinito é igual-a-si mesmo, só se refere a si, já que ele inclui em si diferenças que são tautológicas, que são e não-são diferenças nenhumas. Esse infinito, enquanto relação consigo mesmo, é já, todavia, uma fração, uma cisão, ou seja, ele é uma igualdadeconsigo-mesmo que inclui, no seu interior, a diferença $\left(\$ 162^{\circ}\right)$. Na verdade, não só o infinito, mas também os fragmentos (as frações), produzidos pela cisão própria do infinito, são contraditórios, pois cada um é o contrário de um outro; em cada um o outro já é enunciado ao mesmo tempo que ele. Ou seja: cada um é, em si mesmo, o contrário de si, e isto quer dizer que ele não é puramente para si, uma igualdade consigo mesmo que não tenha nele diferença nenhuma. Neste sentido, não é uma angústia para o filósofo, nem tampouco um problema insolúvel para a filosofia, a pergunta "como a diferença brota da unidade" ou "como o ser-outro sai do uno-infinito", pois o fracionamento, a diferença, já está incluído no idêntico; o que devia ser o igual-a-si-

\begin{tabular}{|l|l|l|l|l|}
\hline Qevista Dialectus & Ano 2 & n. 3 & Julho-Dezembro 2013 & p. 1-17 \\
\hline
\end{tabular}


mesmo já se encontra fragmentado. O igual-a-si-mesmo (a unidade) se fraciona e, como fração, se suprassume como ser-outro; ele é um negativo, pois tem nele mesmo a oposição. Como o igual-a-si (a unidade) deve fracionar-se ou tornar-se o contrário de si, então este fracionamento é uma suprassunção tanto daquilo que ele é quanto de sua fração.

A infinitude faz, como vimos, com que tudo o que é determinado de algum modo seja o contrário dessa determinação. Ela é a alma do movimento dialético da consciência que desde o começo já estava presente, embora só no momento do interior ela venha a ser explicitada claramente; quer dizer, o fenômeno - ou o jogo de forças - já a apresentava, mas só no entendimento é que ela brota livremente. Quando tal infinitude é objeto para a consciência, ou seja, é compreendida por ela como vida, como o que se inverte, se volta sobre si mesma, então a consciência, se refletindo nesse objeto, percebe que ela tem também a mesma estrutura de um diferenciar que não é tal diferenciar e, assim, torna-se consciência-de-si (autoconsciência) $\left(\$ 163^{\circ}\right)$. Isto se dá porque: a) o processo da explicação do entendimento acerca da coisa, que suprassume na lei (no interior) as diferenças determinadas, pondo-as na unidade da consciência, irá revelar a descrição do que é a própria consciência-de-si; b) ao suprassumir as diferenças no interior (na lei geral), o entendimento põe uma nova cisão entre a lei (o interior) e o jogo de forças (o fenômeno), mas, ao mesmo tempo, não reconhece esta diferença, porque, para ele, a força tem a mesma constituição da lei, e c) com a suprassunção dessas diferenças, a consciência concebente está numa relação consigo mesma, ocupando-se apenas de si mesma, embora pareça estar lidando com outra coisa. A consciência não é mais oposta à desaparição, mas a verdade do que desaparece, e o que desaparece é o que permanece, é o próprio real que subsiste em seu desaparecer, sendo, persistindo no seu torna-se constantemente outro. Vimos também que tal consciência tinha por objeto o infinito, dado pela segunda lei como inversão da primeira $\left(\$ 164^{\circ}\right)$. Quando o infinito como vida universal é objeto da consciência, esta é, pois, a consciência da diferença enquanto diferença imediatamente suprassumida, e, assim, torna-se para si mesma consciência-de-si. De fato, na infinitude, no interior do fenômeno, a consciência só faz experiência de si mesma, pois a consciência de um outro, de um objeto, é necessariamente consciência-de-si, ser refletido em si, consciência-de-si mesma em seu ser-outro $\left(\$ 165^{\circ}\right)$.

\begin{tabular}{|l|l|l|l|l|}
\hline Qevista Dialectus & Ano 2 & n. 3 & Julho-Dezembro 2013 & p. 1-17 \\
\hline
\end{tabular}




\section{Referências}

HEGEL, G. F. W. Phänomenologie des Geistes - Hauptwerke in sechs Bänden, Vol. 2. Organização de Wolfgang Bonsiepen e Reinhard Heede. Hamburgo: Wissenschaftliche Buchgesellschaft Darmstadt, 1999.

GADAMER, Hans-Georg. La Dialéctica de Hegel - Cinco Ensayos Hermenêuticos. Tradução de Manuel Garrido. Madrid: Ediciones Cátedra, 2000.

SIEP, Ludwig. Der Weg der Phänomenologie des Geites. Ein einführender Kommentar zu Hegels "Differenzscrift" und "Phänomenologie dês Geistes". Frankfurt: Suhkamp Verlag, 2000. 